\title{
Consumer preferences regarding country of origin for multiple meat products
}

\section{Article}

Accepted Version

Creative Commons: Attribution-Noncommercial-No Derivative Works 4.0

Balcombe, K., Bradley, D., Fraser, I. and Hussein, M. (2016) Consumer preferences regarding country of origin for multiple meat products. Food Policy, 64. pp. 49-62. ISSN 0306-9192 doi: https://doi.org/10.1016/j.foodpol.2016.09.008 Available at https://centaur.reading.ac.uk/67068/

It is advisable to refer to the publisher's version if you intend to cite from the work. See Guidance on citing.

To link to this article DOI: http://dx.doi.org/10.1016/j.foodpol.2016.09.008

Publisher: Elsevier

All outputs in CentAUR are protected by Intellectual Property Rights law, including copyright law. Copyright and IPR is retained by the creators or other copyright holders. Terms and conditions for use of this material are defined in the End User Agreement.

\section{www.reading.ac.uk/centaur}

\section{CentAUR}

Central Archive at the University of Reading

Reading's research outputs online 
Consumer Preferences Regarding Country of Origin for Multiple Meat Products

\author{
Kelvin Balcombe \\ University of Reading \\ Dylan Bradley \\ Agra CEAS Ltd \\ lain Fraser* \\ School of Economics \\ University of Kent \\ And \\ Department of Economics and Finance \\ La Tobe University \\ And \\ Mohamud Hussein \\ Food and Environment Research Agency
}

$25^{\text {th }}$ July 2016

Address for Correspondence:

lain Fraser

School of Economics

University of Kent

Canterbury

Kent, CT2 7NP

i.m.fraser@kent.ac.uk

01227823513

\title{
Acknowledgements:
}

The authors wish to thank two referees for their valuable comments on an earlier version of this manuscript. In addition, we acknowledge funding from UK Department for Environment Food and Rural Affairs (Defra) for the research project (FA0156) on which this article is based. The views expressed in the article are entirely those of the authors and do not necessarily represent the views of Defra. 


\title{
Consumer Preferences Regarding Country of Origin for Multiple Meat Products
}

\begin{abstract}
Despite the growing use of country of origin ( $\mathrm{COO}$ ) information and labels on food, the extent to which consumers really value this information is unclear. In an effort to understand this issue we present results of a hypothetical discrete choice experiment examining consumer willingness-topay for $\mathrm{CoO}$ information about meat and meat products. Our results reveal that CoO information is positively valued for all the food products we consider. However, it is relatively less important compared to other food attributes for a large number of products such as bacon, pizza and ready meals. Our results suggest that consumers do not value very highly CoO information for many of the food products examined. Therefore, if the associated costs of mandatory CoO implementation are sufficiently high this raises questions about the inclusion of this information on food labels.
\end{abstract}

Key Words: Country of origin; mandatory; voluntary; discrete choice experiment.

\section{Introduction}

There is growing interest in the use and development of, country of origin (CoO) information and labels for food in many countries. The reasons for this growth are varied, but are frequently justified by policy makers as a means to correct market failures resulting from asymmetric information especially with regard to meat quality, safety and authenticity. Within the EU mandatory CoO has applied to beef, fruit and vegetables, olive oil, wine, eggs, imported poultry, honey and hops since the 1990/2000s. Japan introduced CoO labels for meat and various other food products in 1997 and the 2002 US Farm Bill introduced CoO labels for multiple unprocessed foods including beef, pork, lamb and various others sold through multiple retailers' grocery stores that took effect in 2009. In July 2016 the Australian Federal government introduced a new system of CoO labels that maintains mandatory labels for most food sold whilst also including a kangaroo symbol plus a graphical indication of the percentage of Australian ingredients by product weight. ${ }^{1}$

Another example of this increasing consideration and use of $\mathrm{CoO}$ information has occurred within the EU in relation to fresh, chilled and frozen meat from pig, poultry, sheep and goat meat. Specifically, Regulation (EU) No 1169/2011 requires mandatory indication of country of origin or place of provenance for unprocessed meat of pigs, poultry, sheep and goats with effect from April, 2015 (via Commission Implementing Regulation (EU) No 1337/2013). Regulation (EU) No 1169/2011 also required the Commission to investigate whether mandatory $\mathrm{CoO}$ labels should be extended to, inter alia, processed meat products such as bacon and sausages as well as products that contain meat products e.g., pepperoni pizza, lasagne, etc. The extension of mandatory CoO labels to this new group of meat products raises several interesting research question.

\footnotetext{
${ }^{1}$ Details are provided on the Australian Federal government website: http://www.foodlabels.industry.gov.au/
} 
First, the proposed extension of mandatory $\mathrm{CoO}$ labels to many more products can in principle be supported if existing estimates of the value placed on $\mathrm{CoO}$ information by consumers are assumed (Umberger, 2010). However, there is no reason to assume that consumer values of $\mathrm{CoO}$ with regard to beef steak apply to products such as pepperoni pizza or streaky bacon. Thus, not only do we need to be sure that consumers' value $\mathrm{CoO}$, but we need to know that what value they place on $\mathrm{CoO}$ for a wide range of products. If it transpires that the absolute values attached to $\mathrm{CoO}$ information vary significantly by product type this raises questions regarding the economic case for extending mandatory $\mathrm{CoO}$ labels based on evidence from a small set of products. In addition, there is no reason to assume that the relative value of $\mathrm{CoO}$ with regard to other product attributes is the same for all products. It is highly unlikely that we can assume that consumers value $\mathrm{CoO}$ to the same extent for all products, simply because it has been found that consumers value it for a specific product that have previously been examined extensively in the literature.

Second, within the literature there is an important distinction made between mandatory versus voluntary CoO labels (Golan, et al., 2001; Roe et al., 2014). Mandatory labelling is usually (but not exclusively) intended to correct market inefficiencies where there is asymmetric information (concerning for example, food safety or production standards) whereas voluntary labels tend to be used to provide quality differentiation by food manufacturers and producers for credence attributes. There are, however, serious questions being raised about the need to extend the coverage of mandatory $\mathrm{CoO}$ labels to ever more food products. Within the EU mandatory $\mathrm{CoO}$ labels were introduced in 1997 for beef because of concerns over BSE and are assumed to be used by consumers to infer product quality (Verbeke and Roosen, 2009). However, evidence in support of mandatory CoO labels for one product does not provide support for their extension to all related or similar products. The extended use of $\mathrm{CoO}$ labels with pig, poultry, sheep and goat meat is derived from an apparent increased consumer expectation for such information. But, if this is the case then this rationale bears more similarity to that supporting voluntary labelling than it does to mandatory labelling. Thus, in the context of recent EU legislation, should mandatory $\mathrm{CoO}$ labels be extended to this more diverse group of meat food products? The difficulty in answering this question definitively partly stems from the fact that $\mathrm{CoO}$ information is a form of extrinsic information about product quality (Caswell and Anders, 2011). In principle a CoO label should help a consumer "infer" or at least form an expectation about quality. However, there is also a point at which a $\mathrm{CoO}$ label can become of greater value, when it is actively sought by consumers because it takes on the form of being a search cue. That is, a consumer sees the label and this indicates within a food search activity the increased likelihood of a (perceived) quality product. 
In this paper, we examine UK consumer preferences for $\mathrm{CoO}$ information for meat and meat products. In assessing consumer preferences, we focus on a choice situation in which all products have a CoO label. Thus, we are not specifically concerned with the choice between a product with and without a CoO label, which has been examined by Klain et al. (2014). This is because the legislative environment in the UK (EU more generally) is such that a CoO label is for a number of meat products now mandatory and for many others there is the widespread adoption of voluntary labels by retailers. Therefore, the key question is no longer the choice between a label or not, but rather the format and whether or not the label is voluntary or mandatory. ${ }^{2}$

In keeping with much of the earlier research, we examine consumer preferences for $\mathrm{CoO}$ information using stated preference methods. Specifically, we have designed and implemented 12 discrete choice experiments (DCE) to assess consumer preferences for $\mathrm{CoO}$ information provided on a food label for a range of meat types and products. The reason for simultaneously implementing 12 DCE is that we need to have sufficient coverage of meat types and products so that we could detect any differences in preferences by type of meat as well as type of product. Furthermore, research on consumer attitudes with regard to $\mathrm{CoO}$ information finds that origin can be important but that this varies with the set of attributes considered, the products considered and the specific consumer segments asked (Grebitus et al., 2012). We also note that Tonsor et al. (2013) have identified the need to conduct research that considers a wide set of products so that researchers can assess if the relative value of $\mathrm{CoO}$ information varies systematically across various types of meat and product.

When considering $\mathrm{CoO}$ it is important to be clear on the definition of "country of origin". This is relatively self-explanatory for unprocessed meat ${ }^{3}$, which is the only form of meat product for which mandatory $\mathrm{CoO}$ labels are in operation within the EU. However, $\mathrm{CoO}$ information needs to be defined more specifically when referring to lightly processed and composite products. In these cases the term can refer to:

(i) the meat (country of birth, rearing and slaughter); or

(ii) the product produced, in which case origin is considered to be the place of last substantial transformation ${ }^{4}$.

\footnotetext{
${ }^{2}$ Tonsor et al. (2013) discuss this specific issue in detail.

${ }^{3}$ See Article 5 of Commission Implementing Regulation (EU) No 1337/2013 for various caveats and exceptions.

${ }^{4}$ This is defined in Article 24 of Regulation (EEC) No 2913/92 of 12 October 1992 establishing the Community

Customs Code as the "last, substantial, economically justified processing or working in an undertaking equipped for that purpose and resulting in the manufacture of a new product or representing an important stage of manufacture“.
} 
So, for example, bacon cured in the UK from Danish pigmeat could be labelled as Danish under the first approach and UK under the second. Any research on $\mathrm{CoO}$ for processed or composite products needs to be aware of these definitions if the research is to be credible.

This research makes several contributions to the literature. First, we have generated a large number of relative and absolute willingness-to-pay (WTP) estimates for $\mathrm{CoO}$ for several meat products considered, with some that have not been considered before in the literature. The importance of these estimates is that they allow us to examine the relative importance attached to $\mathrm{CoO}$ compared to other food label attributes. Importantly, for all our DCE, we specifically focus on the relative value of $\mathrm{CoO}$ given the other products attributes used, because we are employing hypothetical DCE which are more likely to yield inflated point estimates of WTP compared to non-hypothetical DCE. As we explain, our results are revealing with regard to the way in which the relative importance of $\mathrm{CoO}$ varies. Second, our examination of $\mathrm{CoO}$ has focused on the way in which $\mathrm{CoO}$ is included within our DCE design. Specifically, we presented the CoO attribute using both text and graphics. We have also been careful in the selection of countries that products are attributed to as this may have a bearing on how important $\mathrm{CoO}$ might be. Finally, our results have potentially important policy implications going forward because of the coverage of the products we consider and the variation we observe in relative value attached to $\mathrm{CoO}$. Indeed, our results raise questions about the blanket introduction of mandatory $\mathrm{CoO}$ labels when there would appear to be significant variation in consumer preferences by meat and product type.

\section{The Economics of $\mathrm{CoO}$}

The literature on $\mathrm{CoO}$ is large, although the point at which specific consideration of $\mathrm{CoO}$ begins and ends within the literature is far from clear. This can be traced to the fact that $\mathrm{CoO}$ is part of a much wider literature on food labels. Also, what is sometimes considered as research on $\mathrm{CoO}$ is in fact research with minimal emphasis on CoO, a point made by Deselnicu et al. (2013) in a meta-analysis of label research. In their meta-analysis they do not consider $\mathrm{CoO}$ because they argue that $\mathrm{CoO}$ does not provide a sufficiently strong link between a geographic name, a specific production activity or agronomic conditions. Given this distinction, we restrict our review to the literature that considers $\mathrm{CoO}$ simply and specifically as an indicator of country of origin, even though this definition is more often than not hard to enforce on the literature. 
Specifically, we focus our literature review on stated preference research, in particular DCE. ${ }^{5}$ Thus, we do not explicitly consider research that has a theoretical focus or examines market level welfare implications. For readers interested in a theoretical examination of $\mathrm{CoO}$ the recent papers by Roe et al. (2014) and Bonroy and Constantatos (2015) provide excellent summaries. For research on market level impacts and resulting welfare implications for consumers and manufacturers from the introduction of mandatory $\mathrm{CoO}$, Awada and Yiannaka (2012), Baltussen et al. (2013), Joseph et al. (2014) and USDA (2015) offer informative and insightful analysis.

\subsection{CoO and Stated Preference Research}

Umberger (2010) provides a comprehensive survey of the stated preference literature prior to 2010 building on Loureiro and Umberger (2003 and 2007). This review identifies several key findings in relation to the $\mathrm{CoO}$ literature. First, $\mathrm{CoO}$ is perceived by consumers as an extrinsic credence attribute. This needs to be understood when developing a DCE. Second, there is evidence that sample composition (i.e., who you ask to complete the DCE) can impact WTP estimates, especially in relation to $\mathrm{CoO}$. Third, the WTP estimates reported in the literature are product and country specific, as well as being subject to socio-economic factors, tradition and culture. Finally, the value of $\mathrm{CoO}$ is typically context dependent in that it will depend on what other "quality" cues are also being offered to survey respondents. This is because $\mathrm{CoO}$ can act as a cue for other perceived attributes not included within the DCE, e.g., food safety or product quality or support for the "regional" or "local economy. It is for this reason that it is difficult to accurately identify the real value consumers place on $\mathrm{CoO}$.

Since Umberger (2010) there has been continued interest in CoO partly because of the modifications of mandatory $\mathrm{CoO}$ in the US and the implications for Canadian and Mexican beef producers (Lim et al, 2013, 2014, Pouliot and Sumner, 2014 and USDA, 2015), but also because EU legislation has extended mandatory $\mathrm{CoO}$ coverage of food types. ${ }^{6}$ Within the stated preference literature the most common method employed is a hypothetical DCE. A selected summary of the DCE literature since 2010 as it relates to our research is presented in Table 1.

\footnotetext{
${ }^{5}$ There are few revealed preference studies on CoO (Costanigro and McCluskey, 2011) because of a lack of data and products. A recent exception is the study by Hussein et al. (2016) of UK meat. They report a price premium for a UK CoO label of $£ 2$ per kg compared to undeclared (no origin) meat.

${ }^{6}$ The dispute between the US, Canada and Mexico has been the subject of an ongoing dispute at the World Trade Organisation since 2008. The most recent ruling on the dispute found in favour of Canada and Mexico and was issued in December 2015 (https://www.wto.org/english/tratop e/dispu e/cases e/ds384 e.htm). Subsequently the US has repealed its $\mathrm{CoO}$ label legislation in 2016 thus avoiding the imposition of significant countermeasures by Canada and Mexico.
} 
Table 1: Summary of selected WTP Estimates for CoO on Meat Products Since 2010

\begin{tabular}{|c|c|c|c|c|c|}
\hline Study & Product & DCE Price Range & $\begin{array}{l}\text { Countries/ } \\
\text { Regions }\end{array}$ & $\begin{array}{l}\text { WTP } \\
\text { Estimate }\end{array}$ & $\begin{array}{l}\text { Additional } \\
\text { Comments }\end{array}$ \\
\hline $\begin{array}{l}\text { Boeri et al. } \\
(2014)\end{array}$ & Lasagne & $\begin{array}{l}\text { Min price } € 2.8 \\
\text { Max price } € 5.0\end{array}$ & $\begin{array}{l}\text { Ireland } \\
\text { Norway } \\
\text { Italy } \\
\text { France } \\
\text { Germany } \\
\text { Spain }\end{array}$ & $\begin{array}{l}€ 3.44 \\
€ 3.68 \\
€ 4.84 \\
€ 5.97 \\
€ 2.86 \\
€ 3.73\end{array}$ & $\begin{array}{l}\text { Euro }(€) \text { per unit, } \\
\text { weight unknown - } \\
\text { value of knowing if } \\
\text { meat is national } \\
\text { relative to origin } \\
\text { unknown }\end{array}$ \\
\hline $\begin{array}{l}\text { Kallis et al. } \\
\text { (2011) }\end{array}$ & Rabbit & $\begin{array}{l}\text { Min price } € 5.5 \\
\text { Max price } € 6.5\end{array}$ & $\begin{array}{l}\text { Foreign } \\
\text { Spain } \\
\text { Catalonia }\end{array}$ & $\begin{array}{l}-€ 0.636 \\
+€ 0.063 \\
+€ 0.698\end{array}$ & $\begin{array}{l}\text { Euros (€)per kg of } \\
\text { meat - } \\
\text { Restaurateurs } \\
\text { positive } \\
\text { preference for } \\
\text { local, \& Spain } \\
\text { negative for } \\
\text { foreign }\end{array}$ \\
\hline $\begin{array}{l}\text { Kallis and } \\
\text { Gil (2012) }\end{array}$ & Rabbit & $\begin{array}{l}\text { Min price } € 5.50 \\
\text { Max price } € 6.5\end{array}$ & $\begin{array}{l}\text { Foreign } \\
\text { Spain } \\
\text { Catalonia }\end{array}$ & $\begin{array}{l}-€ 0.947 \\
+€ 0.362 \\
+€ 0.5\end{array}$ & $\begin{array}{l}\text { Euros }(€) \text { per kg of } \\
\text { meat - positive } \\
\text { preference local \& } \\
\text { Spain, negative } \\
\text { foreign }\end{array}$ \\
\hline $\begin{array}{l}\text { Klain et al. } \\
\text { (2014) } \\
\text { Direct } \\
\text { Method* }\end{array}$ & $\begin{array}{l}\text { Beef } \\
\text { Steak \& } \\
\text { Pork } \\
\text { Chop }\end{array}$ & $\begin{array}{l}\text { Min price } \$ 0.0 \\
\text { Max price } \$ 5.0\end{array}$ & $\begin{array}{l}\text { No origin } \\
\text { Either US, } \\
\text { Canada, } \\
\text { Mexico or } \\
\text { Australia }\end{array}$ & $\begin{array}{l}\text { Mean value } \\
\text { of origin } \\
\text { information } \\
\text { of US } \$ 1.37 \\
\text { per steak }\end{array}$ & $\begin{array}{l}\text { US \$ for } 12 \mathrm{oz} \\
(0.34 \mathrm{~kg}) \text { of meat - } \\
\text { choice between } \\
\text { no label or meat } \\
\text { with a label but } \\
\text { country not } \\
\text { known }\end{array}$ \\
\hline $\begin{array}{l}\text { Klain et al. } \\
\text { (2014) } \\
\text { Indirect } \\
\text { Method }\end{array}$ & $\begin{array}{l}\text { Beef } \\
\text { Steak \& } \\
\text { Pork } \\
\text { Chop }\end{array}$ & $\begin{array}{l}\text { Min price } \$ 0.0 \\
\text { Max price } \$ 5.0\end{array}$ & $\begin{array}{l}\text { US, Canada, } \\
\text { Mexico } \\
\text { Denmark, } \\
\text { Canada \& US, } \\
\text { Mexico \& US } \\
\text { Canada, } \\
\text { Mexico \& US }\end{array}$ & $\begin{array}{l}\text { Mean value } \\
\text { of origin label } \\
\text { US } \$ 2.15 \text { per } \\
\text { steak }\end{array}$ & $\begin{array}{l}\text { US } \$ \text { for } 12 \text { oz } \\
(0.34 \mathrm{~kg}) \text { of meat - } \\
\text { relative to no } \\
\text { choice - } \\
\text { preference for } \\
\text { CoO when } \\
\text { information } \\
\text { provided }\end{array}$ \\
\hline $\begin{array}{l}\text { Lagerkvist } \\
\text { et al. } \\
(2014)\end{array}$ & $\begin{array}{l}\text { Minced } \\
\text { Beef }\end{array}$ & $\begin{array}{l}\text { Min price } \\
\text { SEK200 } \\
\text { Max price } \\
\text { SEK325 }\end{array}$ & $\begin{array}{l}\text { Sweden, Italy, } \\
\text { and Brazil \& EU } \\
\& \text { non-EU }\end{array}$ & SEK 113.7 & $\begin{array}{l}\text { Swedish Krona } \\
\text { (SEK) per kg-CoO } \\
\text { ranked most } \\
\text { important } \\
\text { attribute }\end{array}$ \\
\hline $\begin{array}{l}\text { Lee et al. } \\
(2015)^{*}\end{array}$ & $\begin{array}{l}\text { Canned } \\
\text { Ham }\end{array}$ & $\begin{array}{l}\text { Min KRW3000 } \\
\text { Max KRW3,900 }\end{array}$ & $\begin{array}{l}\text { Domestic } \\
\text { Imported }\end{array}$ & $\begin{array}{l}\text { KRW557upto } \\
\text { KRW947 }\end{array}$ & $\begin{array}{l}\text { Korean Won } \\
\text { (KRW) - used non- } \\
\text { hypothetical DCE - } \\
\text { 340gram can }\end{array}$ \\
\hline $\begin{array}{l}\text { Lim et al. } \\
\text { (2013) }\end{array}$ & $\begin{array}{l}\text { Beef } \\
\text { Steaks }\end{array}$ & $\begin{array}{l}\text { Min price } \$ 5.0 \\
\text { Max price } \$ 16.0\end{array}$ & $\begin{array}{l}\text { US to Australia } \\
\text { US to Canada }\end{array}$ & $\begin{array}{l}-\$ 8.4 \\
-\$ 6.1\end{array}$ & $\begin{array}{l}\text { Strip loin Steak } \\
\text { US\$ per lb -need } \\
\text { to reduce price for } \\
\text { imported meat }\end{array}$ \\
\hline $\begin{array}{l}\text { Lim et al. } \\
(2014)\end{array}$ & $\begin{array}{l}\text { Beef } \\
\text { Steaks }\end{array}$ & $\begin{array}{l}\text { Min price } \$ 5.0 \\
\text { Max price } \$ 16.0\end{array}$ & $\begin{array}{l}\text { US to Australia } \\
\text { US to Canada }\end{array}$ & $\begin{array}{l}-\$ 7.33 \\
-\$ 5.75\end{array}$ & $\begin{array}{l}\text { Strip loin Steak } \\
\text { US\$ per lb - WTP }\end{array}$ \\
\hline
\end{tabular}


moderated by

attitudes to

perceived food-

safety levels.

\begin{tabular}{|c|c|c|c|c|c|}
\hline $\begin{array}{l}\text { Lusk et al. } \\
(2014)^{* \#}\end{array}$ & $\begin{array}{l}\text { Beef } \\
\text { Steak \& } \\
\text { Pork } \\
\text { Chop }\end{array}$ & $\begin{array}{l}\text { Min price } \$ 0.0 \\
\text { Max price } \$ 4.0\end{array}$ & $\begin{array}{l}\text { US, Canada, } \\
\text { Mexico } \\
\text { Denmark, } \\
\text { Canada \& US, } \\
\text { Mexico \& US } \\
\text { Canada, } \\
\text { Mexico \& US }\end{array}$ & $\begin{array}{l}\text { Weighted } \\
\text { average of US } \\
\$ 1.68\end{array}$ & $\begin{array}{l}\text { US } \$ \text { for } 12 \mathrm{oz} \\
\text { ( } 0.34 \mathrm{~kg} \text { ) of meat - } \\
\text { controlling for } \\
\text { beliefs premium } \\
\text { for US relative all } \\
\text { others }\end{array}$ \\
\hline $\begin{array}{l}\text { Meas et al. } \\
\text { (2014) }\end{array}$ & $\begin{array}{l}\text { Beef } \\
\text { Steak }\end{array}$ & $\begin{array}{l}\text { Min price } f 4.88 \\
\text { Max price } f 8.82\end{array}$ & $\begin{array}{l}\text { GB to France } \\
\text { GB to Canada } \\
\text { GB to Germany } \\
\text { GB to } \\
\text { Argentina } \\
\text { GB to US }\end{array}$ & $\begin{array}{l}-£ 4.39 \\
-£ 4.09 \\
-£ 4.06 \\
-£ 4.67 \\
-£ 4.34\end{array}$ & $\begin{array}{l}\text { Beef steak } 375 g \\
\text { pack. CoO - GB, } \\
\text { France, Germany, } \\
\text { Argentina, US and } \\
\text { Canada. GB is the } \\
\text { reference level per } \\
\text { pack }\end{array}$ \\
\hline $\begin{array}{l}\text { Morkbak } \\
\text { et al. } \\
\text { (2010) }\end{array}$ & $\begin{array}{l}\text { Minced } \\
\text { Pork }\end{array}$ & $\begin{array}{l}\text { Min price DKK } \\
20 \\
\text { Max price DKK } \\
120\end{array}$ & $\begin{array}{l}\text { Domestic } \\
\text { Foreign }\end{array}$ & $\begin{array}{l}\text { DKK } 27.94 \\
\text { DKK } 36.97\end{array}$ & $\begin{array}{l}\text { Danish Krona } \\
\text { (DKK) 500g } \\
\text { package }\end{array}$ \\
\hline $\begin{array}{l}\text { Pouta et al. } \\
\text { (2010) }\end{array}$ & $\begin{array}{l}\text { Broiler } \\
\text { Meat }\end{array}$ & $\begin{array}{l}\text { Min price } € 6.0 \\
\text { Max price } € 16.0\end{array}$ & $\begin{array}{l}\text { Finland to } \\
\text { Denmark } \\
\text { Finland to } \\
\text { Brazil } \\
\text { Finland to } \\
\text { Thailand }\end{array}$ & $\begin{array}{l}30-40 \% \\
46-77 \% \\
46-92 \%\end{array}$ & $\begin{array}{l}\text { Euros }(€) \text { per } \mathrm{kg}- \\
\text { the reduction in } \\
\text { WTP resulting } \\
\text { from non-Danish } \\
\text { are bigger }\end{array}$ \\
\hline
\end{tabular}

\subsubsection{Product Coverage}

When we consider product coverage in the literature, we find that the majority of studies are for beef with many types of meat absent. Furthermore, there is little research that has considered meat products or meat as an ingredient. One exception is Boeri et al. (2014) who examined consumer WTP for $\mathrm{CoO}$ employing beef lasagne. ${ }^{7}$ In this research the authors focus on meat authenticity and food safety with $\mathrm{CoO}$ included within the attribute set, but in a non-specific format.

\subsubsection{Country of Origin Framing}

How $\mathrm{CoO}$ has been presented and framed is frequently ad hoc and not always in keeping with legislation. This aspect of survey design raise questions as to the way in which existing estimates of WTP for $\mathrm{CoO}$ should be interpreted. An example of study that employs key aspects of $\mathrm{CoO}$ legislation is Tonsor et al. (2013) who employed label types that captured the interaction between USDA label categories and preferences for specific label types expressed by various groups within the US meat

\footnotetext{
${ }^{7}$ Carlsson et al. (2014) in a study of CoO in Sweden consider both bacon and a ready meal made with beef. However, the study does not detail what the ready meal is or the serving size offered.
} 
industry. Similarly, Lagerkvist et al. (2014) employed a CoO attribute for beef based on EU Regulation $1760 / 2000$. They also compared the mandatory label with an alternative that simply stated if meat was from within the EU or not (i.e., non-EU). In contrast, many studies do not present CoO information within the existing or expected legislative context (e.g., Kallis et al., 2011; Kallis and Gil, 2012). Morbak et al. (2010) examine CoO, but the focus of this research is on the way price levels should be set within a DCE (i.e., the choke price effect). Finally, Lee et al. (2015) employed two levels for origin: domestic or imported. In this study the focus was less on origin but more on the level of salt in the product. Interestingly, origin was more highly valued than reduced salt.

Another important issue is how $\mathrm{CoO}$ is presented within the survey instrument: text only; graphic only; or both. Many papers employ text only, whereas others use text and graphics (that can include flags and/or maps) to indicate CoO (e.g., Pouta et al., 2010, Lagerkvist et al., 2014). We contend that more thought is required in terms of how a $\mathrm{CoO}$ attribute is presented both from a legal perspective as well as from the survey design point of view in terms of understanding the choice as well as specific aspects of the choice context.

There is also significant variation in how $\mathrm{CoO}$ is framed with regard to home and other countries. Boeri et al. (2014) and Klain et al. (2014) both consider the difference between knowing or not knowing, the $\mathrm{CoO}$. This distinction is important if the policy choice is between the presence or absence of $\mathrm{CoO}$ information. Other studies simply indicate the home country and refer to imports without specifically identifying a country (e.g., Kallis and Gil, 2012, Lee et al., 2015). Another approach is to use a set of countries that might supply the product to see if differences in domestic preferences are revealed. For example, Meas et al. (2014) considered UK consumer attitudes to domestic and imported beef from several countries. Their results reveal the necessary price reductions that imported beef would need to be subject to for UK consumers to consider purchasing. These findings are typical of those reported by other studies in the literature (e.g., Lim et al., 2013, 2014, and Klain et al., 2014). There are also studies that consider EU/non-EU versus specific country labels (e.g., Lagerkvist et al., 2014).

Another feature of the literature is that there is very little research that considers products that have multiple country $\mathrm{CoO}$ information. One exception is Lagerkvist et al. (2014) who indicate the country in which an animal was born, fattened, slaughtered and the meat packaged which is required for beef as a result of EU Regulation 1760/2000/EC. Lusk et al. (2014) have also examined what happens when respondents are confronted with multiple origin labels. They note that respondents are pessimistic about the information conveyed in these labels, tending to infer the origin is much more likely to be from the less-preferred origin. 
Finally, the issue of how $\mathrm{CoO}$ it is understood by survey respondents has been used to examine the distinction between beliefs and preferences. Lusk et al. (2014) examine why a consumer may not wish to buy a product because of $\mathrm{CoO}$ information. This could occur either because they do not value the information sufficiently to pay a price premium for the product, or the consumer does not believe the information that is provided. This approach to valuation reveals interesting insights into the values attributable to $\mathrm{CoO}$ information once beliefs are controlled for.

\subsubsection{DCE Design and Implementation}

There is significant variation in DCE design and implementation. For example, there is variation in how the DCE survey instrument asks the respondents to answer questions. Some researchers have used a dual response DCE (Kallis et al., 2011; Kallis and Gil, 2012) whereas Lagerkvist et al. (2014) take a marketing approach to survey design (especially the selection and use of attributes) data collection and data analysis. There are also hypothetical and non-hypothetical DCE. Most studies are hypothetical, but Klain et al. (2014) and Lee et al. (2015) provide examples of non-hypothetical DCE. The main reason for undertaking non-hypothetical DCE is to try and minimise hypothetical bias which has been identified by List and Gallet (2001), who report that survey respondents can overstate WTP by up to three times. Similarly, Moser et al. (2014) report results that show hypothetical DCE yielding WTP estimates that are somewhat higher than those reported from experiments that involve real incentive payments. In contrast, Lusk and Schroeder (2004) report minimal levels of hypothetical bias for a hypothetical DCE.

To implement a non-hypothetical DCE Klain et al. (2014) and Lee et al. (2014) both offer a participation fee. In the case of Klain et al. (2014) the fee was supplemented with a free cut of meat. Klain et al. (2014) offered a fee that could be less than the price finally paid as a result of the choices made during the experiment. For Lee et al. (2015) participants were told that one choice from eight made would be selected at random and the choice made will be binding i.e., the participant has to pay for the choice made. ${ }^{8}$ The attraction of this approach is that it ensures that respondents behave in an incentive compatible manner. However, although both studies offer interesting approaches to dealing with hypothetical bias, non-hypothetical DCE remain difficult to employ in contexts in which actual products do not exist or there is a hypothetical attribute included in the set of attributes that are of interest to the researcher.

\footnotetext{
${ }^{8}$ Lee et al. (2015) note that not all of the product options provided are actually available which means that an element of deception is employed. This trade-off between trying to reduce hypothetical bias and what is deemed appropriate in terms of survey practice, such as the use of deception is an ongoing topic of discussion within the literature (Colson et al., 2015).
} 
Another important feature of DCE design, noted by Gao and Schroeder (2009), is that the set of attributes as well as the levels employed can impact WTP estimates in relation to CoO. For example, Lagerkvist et al. (2014) note how information on animal welfare increased product selection when using a EU/non-EU label. Therefore, it would appear that the inclusion of an attribute relating to animal welfare can impact on the relative preference for $\mathrm{CoO}$ as the attributes can be conflated by respondents or one can be used to infer something about the other. Finally, what is also clear from the literature presented in Table 1 is that there no agreed set of attributes to always include within a survey or DCE examining CoO. ${ }^{9}$

\subsection{WTP for $\mathrm{COO}$}

A striking feature of the literature is the positive WTP estimates reported for national and/or local products compared to imports. Also the magnitude of the $\mathrm{CoO}$ WTPs estimates reported are significant, often at least $50 \%$ of the mid-point of the price range employed in a DCE, regardless of the type of food or country in which the research has been conducted. In contrast, FCEC $(2013,2014)$ report lower much lower WTP estimates although the survey methods employed lack theoretical rigour. However, these estimates are often cited in arguments against the implementation of mandatory CoO labels. But, only focusing on the magnitude of WTP estimates potentially ignores the importance of understanding the relative value of $\mathrm{CoO}$ information.

Looking beyond the magnitude of the WTP estimates reported we find potentially important and consistent results with respect to the relative value of $\mathrm{CoO}$. For example, in many of the studies considered in Table 1, $\mathrm{CoO}$ or a related regional/national label, comes out as being of greatest relative importance given the other attributes included in survey designs. Indeed, the relative value attached to $\mathrm{CoO}$ in some studies is very large. For example, Lim et al. (2013) report that even when imported beef includes various attributes all of which are positively valued by consumers the resulting increase in WTP is still not enough to compensate for the price reduction required by consumers. In fact, it is the relative value placed upon $\mathrm{CoO}$ that appears to be the most consistent feature of the literature, regardless of the specific type of meat considered or the focus of the DCE. However, Carlsson et al. (2014) observe that the relative importance attached to CoO especially for fresh beef is a consistent result. But, they also note that for more heavily processed products that the relative value of $\mathrm{CoO}$ declines.

\footnotetext{
${ }^{9}$ Lusk and Briggeman (2009) (p. 191) in a general food setting study of consumer valuation of food attributes found that origin ranked as least important. They suggest this is because origin is a proxy for other aspects of food safety that reflects beliefs as opposed to preferences (Lusk et al., 2014) and/or also because of specific types of product considered in the literature e.g., beef.
} 


\section{DCE Design and Implementation}

\subsection{Products and Attributes}

We began by identifying the number of products to consider and the attributes to use in the DCE along with units of measurement. To inform product choice we examined the UK meat consumption statistics drawn from the Defra Monthly Living Costs and Food Survey ${ }^{10}$. In total 12 products were identified, based on consumption, so as to provide sufficient coverage of meat products available to UK consumers. The products selected are composed of four fresh (unprocessed) meat products (i.e., Chicken breast, Lamb Leg, Pork Leg and Turkey Mince), four partially processed meat products (i.e., Pork Sausage, Beef Burgers, Gammon Steak and Streaky Bacon) and four products that contain meat as an ingredient (i.e., Chicken Curry, Beef Lasagne, Chicken Pie and Pepperoni Pizza).

Given the logistics involved with implementing 12 DCEs simultaneously we asked respondents to complete two DCEs within the version of the survey they were selected to complete. To do this we paired the 12 products yielding six survey versions. The pairing of products was as follows:

- $\quad$ Chicken Breast Fillets and 14" Pepperoni Pizza

- $\quad$ Turkey Mince and Pork Sausages

- $\quad$ Pork Leg Joint and Streaky Bacon

- $\quad$ Lamb Leg Joint and Chicken Madras Curry

- $\quad$ Beef Burgers and Shortcrust Pastry Chicken Pie

- Gammon Steaks and Beef Lasagne

In the final set of choice cards, we randomized the order of the products so as to minimise any order effects in the data collected.

Having identified the set of products, we then determined the attributes required to implement the DCEs. These attributes were determined in part by reference to the literature, feedback from policy experts and results obtained from a small pilot study. We employed a relatively homogenous group of attributes, albeit with variation across certain attributes for all 12 products. Thus, we varied the set of countries as part of the $\mathrm{CoO}$ attribute presented to respondents to reflect likely sources of meat supply.

\footnotetext{
${ }^{10}$ For more details see https://www.gov.uk/government/collections/family-food-statistics.
} 
After designing an initial version of the DCE survey instrument and further discussion with policy experts an initial version of the survey instrument was piloted with a small group of respondents $(n=30)$. Basic analysis of the data revealed that all attribute parameter estimates had the expected signs and were statistically significant. Also, when asked about ease of survey completion and understanding the respondents indicated that the survey instrument was relatively easy to understand and straightforward to complete. As a result we moved to generating the final version of the survey instrument. The set of five DCE attributes are:

Price - For this attribute, the range of values was jointly determined in combination with product specific size and description of each product type determined by reference to those most commonly on sale in UK shopping outlets. An extensive search of online and in-store prices of the selected product types was undertaken prior to final selection of price points.

CoO-Our approach was to select four levels: UK; a specific EU country (differing by product); a generic EU option; and a specific non-EU country. ${ }^{11}$ To determine which countries to employ we considered trade data on meat and meat products reported in various publications (BPEX 2013a,b and EBLEX $2014 a, b)$. Based on the data, we identified countries that provide the highest level of import for each meat type and the source of meat used in various processed products. We note that in relation to processed food there is very little information regarding the original source of meat used and the relative quantity within the food. ${ }^{12}$ This lack of data also meant that it was difficult to create a CoO attribute for meat as an ingredient that described different countries with regard to $\mathrm{CoO}$. This meant that we did not explicitly use the statement, "Place of animal's birth, rearing and/or slaughtering" and instead decided to state that the meat in question was from a specific country with the text for the $\mathrm{CoO}$ attribute different for fresh/chilled/frozen products compared to processed meat and meat used as an ingredient. Importantly, we followed the legislation for fresh/unprocessed meat (as it is there), but as there is no legislation for processed products we had to make this simplification (which, by the way, would almost certainly have to be the case if introduced for space reasons alone on actual packaging). ${ }^{13}$

\footnotetext{
${ }^{11}$ Font i Furnols et al. (2011) employ a similar approach to country selection in a conjoint study of CoO of lamb. They find that $\mathrm{CoO}$ is the most important attribute in all countries surveyed e.g., Spain, France and UK.

${ }^{12}$ Defra (2012) noted in regard to the production of chicken curry that identifying the origin of chicken is "complex" as a result of the level of processing. Typically, chicken breast is imported, although source is not always clearly identified, although chicken used in manufactured foods is frequently imported from Brazil and Thailand.

${ }^{13}$ Our $\mathrm{CoO}$ attribute only relates to meat either for unprocessed or processed products. This was made clear to survey respondents prior to undertaking the choice task. This approach to $\mathrm{CoO}$ identification is consistent with how the legislation has been implemented since April 2015. However, as noted by a referee there is the need in future research to also examine the value of information for $\mathrm{CoO}$ for processed products that include several ingredients from several countries.
} 
Product Quality - For this attribute the choice of terms to use (i.e., Basic, Choice and Premium) was decided by focus group and pilot results. The inclusion of an attribute to describe product quality meant that we could implicitly capture aspects of each product that relate to taste or other quality related characteristics. In many ways the use of this type of information on food is to act as a cue indicating all of those characteristics that constitute "quality" but are not stated explicitly.

Farming System (Production) - Our final choice for this attribute was Organic or Conventional. We made this choice as these two production systems represent the vast majority of meat production on the market and are familiar to consumers.

Quality Assurance - For this attribute our choice was no label, Freedom Food ${ }^{14}$ and the International Quality label. We initially included the Red Tractor standard within the survey design used in our pilot study. The Red Tractor has been used in an earlier DCE CoO on beef by Maes et al. (2014). However, it was decided that this might cause confusion as it combines a tractor with the UK flag. Although this assurance mark can be used with products produced outside the UK we decided that the flag that is within the common form of the label may confuse consumers as to the actual country of origin of the product under consideration.

The final set of 12 products used, the attributes and associated levels used in our DCEs are presented in Table 2.

Table 2: Products, Attributes and Levels

\begin{tabular}{llll}
\hline Product & Chicken Breast (500g) & Pork Sausages (450g) & Chicken Pie(550g) \\
\hline CoO & Netherlands and Thailand & Denmark and Thailand & Ireland and Brazil \\
CoO Words & Reared and Slaughtered & Meat Origin & Meat Origin \\
Production & Conventional or Organic & Conventional or Organic & Conventional or Organic \\
Product Quality & Basic, Choice, Premium & Basic, Choice, Premium & Basic, Choice, Premium \\
Farm Assurance & International, Freedom & International, Freedom & International, Freedom \\
& Food Or None & Food Or None & Food Or None \\
Prices (f) & 3.00, 4.50, 5.50, 7.50 & 1.40, 1.80, 2.39, 3.05 & 2.00, 2.99, 3.49, 3.99 \\
\hline Product & Turkey Mince (400g) & Streaky Bacon (300g) & Pepperoni Pizza (14") \\
\hline CoO & Germany and Thailand & Denmark and Brazil & Italy and USA \\
CoO Words & Reared and Slaughtered & Meat Origin & Meat Origin \\
Production & Conventional or Organic & Conventional or Organic & Conventional or Organic \\
Product Quality & Basic, Choice, Premium & Basic, Choice, Premium & Basic, Choice, Premium
\end{tabular}

\footnotetext{
${ }^{14}$ We note that Freedom Food became RSPCA Assured during 2015: http://www.thegrocer.co.uk/buying-and-
} supplying/health/rspca-assured-scheme-plans-200-certification-hike/520304.article 


\begin{tabular}{|c|c|c|c|}
\hline Farm Assurance & International, & $\begin{array}{l}\text { International, Freedom } \\
\text { Food Or None }\end{array}$ & $\begin{array}{l}\text { International, Free } \\
\text { Food Or None } \\
1.99,2.95,3.75,5.25\end{array}$ \\
\hline Prices (f) & 2.00, 2.50, 3.50, 4.19 & $1.79,2.50,2.99,3.79$ & $3.75,5.25$ \\
\hline $\mathrm{CoO}$ & Denmark and Brazil & Ireland and Brazil & Germany and Brazil \\
\hline CoO Words & Reared and Slaughtered & Meat Origin & Meat Origin \\
\hline Production & Conventional or Organic & Conventional or Organic & Conventional or Organic \\
\hline Product Quality & Basic, Choice, Premium & Basic, Choice, Premium & Basic, Choice, Premium \\
\hline Farm Assurance & $\begin{array}{l}\text { International, Freedom } \\
\text { Food Or None }\end{array}$ & $\begin{array}{l}\text { International, Freedom } \\
\text { Food Or None }\end{array}$ & $\begin{array}{l}\text { International, Freedom } \\
\text { Food Or None }\end{array}$ \\
\hline Prices (f) & $4.50,6.50,8.99,12.49$ & $2.09,3.00,3.29,4.00$ & $1.75,2.50,4.00,5.99$ \\
\hline Product & Lamb Leg (1.5kgs) & Gammon Steaks (225g) & Chicken Curry (400g) \\
\hline $\mathrm{CoO}$ & Ireland and New Zealand & Denmark and USA & Netherlands and Thailand \\
\hline CoO Words & Reared and Slaughtered & Meat Origin & Meat Origin \\
\hline Production & Conventional or Organic & Conventional or Organic & Conventional or Organic \\
\hline Product Quality & Basic, Choice, Premium & Basic, Choice, Premium & , Choice, Premium \\
\hline Farm Assurance & $\begin{array}{l}\text { International, Freedom } \\
\text { Food Or None }\end{array}$ & $\begin{array}{l}\text { International, Freedom } \\
\text { Food Or None }\end{array}$ & $\begin{array}{l}\text { International, Freedom } \\
\text { Food Or None }\end{array}$ \\
\hline Prices (f) & $9.50,12.99,13.50,15.99$ & $2.49,3.50,4.00,5.50$ & $1.49,2.65,3.60,3.99$ \\
\hline
\end{tabular}

As can been observed in Table 2 there is variation for $\mathrm{CoO}$ in terms of selection of countries as well as the text used on the choice cards. There is also variation associated with the price attribute for each meat product as would be expected.

\subsection{DCE Survey Treatments and Design}

An important feature of study was the examination of the use of text and text and graphic information to indicate $\mathrm{CoO}$. Although the current legislation permits, but does not mandate, the use of flags to signify $\mathrm{CoO}$, we considered it important to see if the exclusion/inclusion of a flag in addition to text impacted on resulting WTP estimates. To enable us to investigate the impact of text and text and flag in relation to $\mathrm{CoO}$, we employed two experimental treatments:

I. Treatment 1 (T1) - text only to describe $\mathrm{CoO}$

II. Treatment 2 (T2) - text and flag to describe $\mathrm{CoO}$

We implemented the treatments asking each respondent to complete one DCE with a CoO text only and a version with $\mathrm{CoO}$ text and flag. The order of the text and text and flag DCE was randomised over the survey for all product combinations.

Having identified our attributes, their associated levels and treatments, we moved to the generation of choice sets. We took a conservative approach to the design assuming a multinomial logit (MNL) utility specification with uninformative priors on all parameters and employing D-error efficiency. Our design was produced using Ngene version 1.1.1 (Choice Metrics 2012). In total, we generated 24 
choice cards for each DCE with each card offering a respondent two choices and an opt-out "no buy" option. The "no buy" option is not given a specific set of attribute levels as there are many ways a consumer might spend their budget other than on the products being offered in the choice setting.

Finally, to avoid respondent fatigue, these cards were blocked into four groups of six cards (Louviere, Hensher and Swait, 2000). Given that we randomizes the order of text (T1) and text and flag (T2) by product combinations meant that we generated in total eight versions of each survey (4 blocks times 2 treatments) yielding a total of 48 survey versions ( 6 surveys times 8 versions). An example of a typical choice card for treatment $\mathrm{T} 2$ is shown in Figure 1. In Figure 1, the $\mathrm{CoO}$ attribute is a combination of text and flag.

Figure 1: Example of a Choice Card (Treatment with Flag and Text)

Imagine you are buying $1.5 \mathrm{Kgs}$ Pork Leg Joint. Which option would you choose?

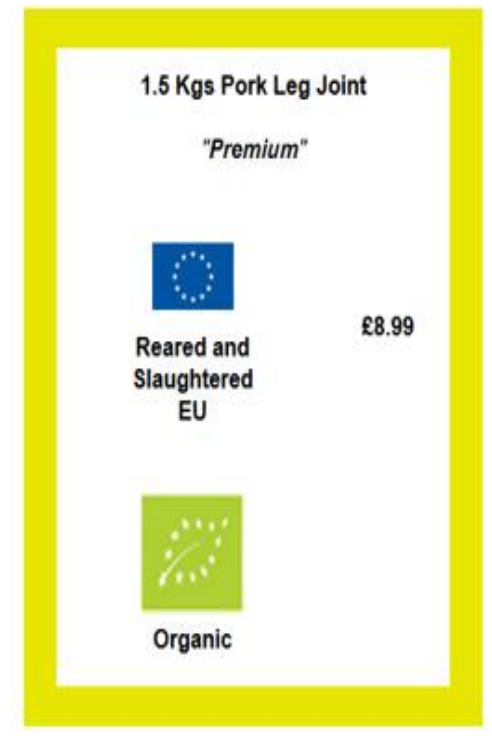

I would buy:

Option A:

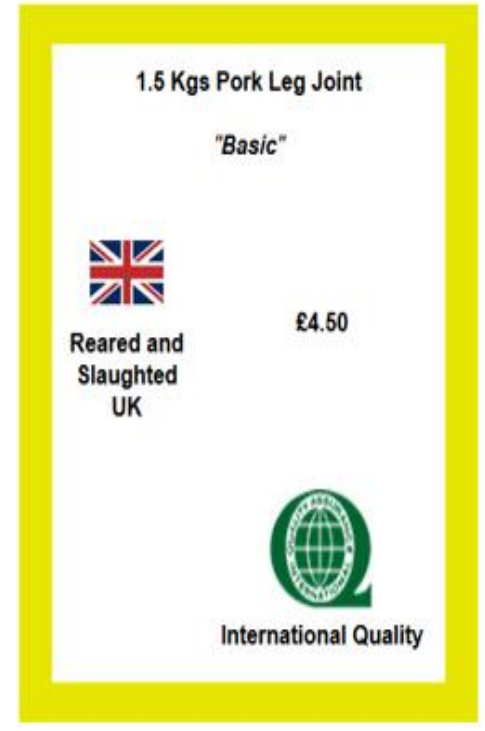

Option B:

Would you buy this product (either Option A or B) if it was available?

(Please select one option.)

Yes

No

\subsection{Data Collection}

We collected our DCE data by distributing our survey online to a UK-wide representative sample employing a market research company. The data collection was implemented so as to ensure that each version of the survey achieved a representative sample for a set of predetermined parameters 
(i.e., age, gender, location, income). ${ }^{15}$ In total, with the six survey versions, we collected data from 2,951 respondents, yielding approximately 490 respondents per DCE survey version. For each of the 12 DCE this meant that we had more than 8,800 data points.

Given the variation in meat products being considered we needed to be aware of various cultural beliefs. Thus, we employed a number of screening questions to ensure that survey participants did not receive a version of the survey that might compromise personal beliefs or offend. The collection of socio-economic data as well data on basic shopping habits was used to check for sample representativeness. ${ }^{16}$

\section{Model Estimation and Results}

The DCE methodology is based primarily based on Lancaster's theory of demand, with associated choice models supported by random utility theory. To analyse our DCE data we employ a Bayesian (random parameter) mixed logit (MXL) specification to estimate the preference parameters of respondents. Within Bayesian circles this model is also referred to as the Hierachical Bayesian Logit.

There are several reasons why we employ a Bayesian specification to undertake model estimation. First, by employing Bayesian methods we are able to undertake model comparisons in a consistent manner (Balcombe et al., 2009) by estimating logged marginal likelihoods. Second, it is noted within the literature that Bayesian methods are better able to deal with issues of empirical identification associated with Classical approaches to simulation (Greene and Hensher, 2010). Third, by adopting, as we do, a WTP space approach to model estimation, model parameters are directly interpretable as WTPs. Thus, when employing Bayesian methods we can adopt meaningful prior distributions that capture a priori bounds for our WTPs (Balcombe et al., 2010).

\subsection{Model Specification}

Formally, let $x_{i j s}$ denote a $k \times 1$ vector of attributes from the DCE presented to the $j$ th individual $(j=1, \ldots$, $J)$ in the ith option $(i=1, \ldots l)$ of the $s$ th choice set $(s=1, \ldots, S)$.. Let $U_{i j s}$ be the utility that the $j$ th individual attains from $x_{i j s}$. In addition, let $y_{i j s}$ be an indicator variable that is equal to one if the $j$ th individual chooses the ith option within the sth choice set, and zero otherwise. Next we define $f(x)$ and $f\left(x_{j}\right)$ to denote the density and conditional density functions and $F(x)$ and $F\left(x_{j}\right)$ to be the associated cumulative distributions.

\footnotetext{
${ }^{15}$ See Appendix A Table A1 for details of descriptive statistics for the six groups of survey respondents.

${ }^{16} \mathrm{~A}$ copy of the survey instrument used in this research is provided in Appendix B.
} 
An individual $j$ is assumed to receive linear utility from the ith choice in the sth choice set, although the parameters may be transformed. Consequently, the utility function is of the form:

$$
U_{i j s}=x_{i j s}^{\prime} t\left(\beta_{j}\right)+e_{i j s}
$$

where $\beta_{j}$ is a $(k \times 1)$ vector describing the preferences of the $j$ th individual and $t($.$) is some$ transformation of the parameters. $\beta_{j}$ are typically assumed to be an independently and identically normally distributed vector with mean $\alpha$ and variance covariance matrix $\Omega$. However, the function $t$ (.) can take a number of forms. For example, we might employ the log-normal for the cost/price coefficient and the normal distribution for all other parameters. Thus, to estimate the MXL in WTP space, we can employ a re-parameterisation of the form:

(2) $t\left(\beta_{j}\right)=t_{1}\left(\beta_{1 j}\right)\left(1, t_{2}\left(\beta_{2 j}\right), \ldots, t_{k}\left(\beta_{k j}\right)\right)^{\prime}$

where the quantities $t_{2}\left(\beta_{2 j}\right), \ldots, t_{k}\left(\beta_{k j}\right)$ are the marginal rates of substitution (MRS) with the numeraire being the first attribute, which will always be the price or cost attribute within the given DCE. Finally, the error term $e_{i j s}$ in equation (1) is assumed to be extreme value (Gumbel) distributed, independent of $x_{i j s}$ and uncorrelated across individuals or choices.

As already noted the re-parameterisation shown in equation (2) provides important benefits. For example, when we estimate our model in preference space we would first estimate marginal utilities and the various MRS are derived from these. By estimating in WTP space the MRS are estimated directly and it has been found that this approach can significantly reduce the instability associated with WTP estimates recovered from preference space (Balcombe et al., 2010). Moreover, because the parameters are directly interpretable as WTPs, when adopting a Bayesian approach more meaningful prior distributions can be adopted that reflect a priori bounds for these WTPs (Balcombe et al., 2010).

Next define the set of all stated choices by an individual as $Y=\left\{y_{i j s}\right\}_{i j s}$, the set of options given to the $j$ th individual is $X_{j}=\left\{x_{i j s}\right\}_{i s}$, the set of all option sets given to all respondents is $X=\left\{X_{j}\right\}_{j}$ and the set of all data is $D=\{Y, X\}$. Finally, we describe the collection of all parameters describing the model as $\Theta=(\alpha, \Omega)$ with the set $\left\{\beta_{j}\right\}_{j}$ denoted as $B$ such that it refers to $B$ as latent data.

Given this notation we can define the probability that an individual $j$ will make a given set of choices. Formally, 
(3) $p_{j}=\prod_{n=1}^{N} \prod_{i=1}^{I_{n}}\left(\frac{e^{t\left(\beta_{j}\right)^{\prime} x_{j s}}}{\sum_{i=1}^{I_{n}} e^{t\left(\beta_{n}\right)^{\prime} x_{i j s}}}\right)^{y_{j i n}}$

from which the likelihood function can be constructed. Within a Bayesian setting we adopt a prior distribution $\pi(\Theta)$ which is multivariate normal for $\alpha$ and Inverse Wishart (IW) for $\Omega$. Specifically, the prior for $\alpha$ we assume is

(4) $\alpha \sim f_{N}\left(\alpha \mid \mu, A_{0}\right)$

where $\mu$ is the mean and $A_{0}$ is a diagonal matrix. With respect to the prior for $\Omega$ we employ the following

(5) $\Omega \sim f_{I W}\left(\Omega \mid T_{0}, v_{0}\right)$

Given all our priors we employ the following set of hyper parameters $\mu, A_{0}, T_{0}$ and $v_{0}$. Our choice of priors is determined by reference to the literature as well as our own experiments with the data to check for robustness of results generated. In particular, we specified the means (i.e., the priors for $\alpha$ ) to be at the mid-range of the price distribution for each commodity, with the standard deviation to be equal to the difference between the middle and upper and lower extremes that we observed in the market place. Such priors are both meaningfully informative, but allow for the data to largely dominate the priors.

\subsection{Model Estimation and Selection}

Bayesian estimation of the MXL has not been extensively exploited, although the methods are now well developed. The approach to estimation of the MXL is implemented by simulating the posterior distribution of the mean and variance/covariance of the preference parameters $\left\{\beta_{j}\right\}$. The algorithm used to undertake the simulation is referred to as the "the sampler". To ensure that estimation has been implemented so as to yield model convergence we observe the values of the parameters sequentially generated by the sampler. To formally test for convergence a modified t-test is employed for which the null hypothesis is no-difference between the first and second half of the sampled values (with a sub-set of values removed from the middle). We also minimise problems of dependence in estimation by only using one value in a sequence generated by the sampler (i.e., 1 in 100 draws). This 
is called the skip method and this can be set at a frequency of skip so as to minimise the degree of correlation.

Finally, to select our preferred model specifications we estimate logged marginal likelihoods (MargLLs). Within a Bayesian specification MargLLs are sufficient for us to make model comparisons. Formally, the support for each model $(M)$ was evaluated by calculating the marginal likelihood $(f(Y \mid M))$ where $M$ represents the model, $Y$ is the observed data. Each model has its own marginal likelihood for the observed data, and we calculate this for each model that we estimate. Importantly, the MargLL takes into account the number of parameters that are estimated which means that we do not need to make adjustments when judging the difference between models (Balcombe et al., 2015).

\section{DCE Results}

All DCE data was estimated using a MXL specification estimated in WTP space. In keeping with assumptions typically employed in the literature, all attributes are assumed to be random parameters with normal distributions employed other than price which was modelled as a log-normal distribution.

Given the set of attributes employed our model specification is as follows:

(6) $U_{i j s}=x_{i j s}^{\prime} t\left(\beta_{j}\right)+e_{i j s}$

where

$x_{i j s}^{\prime} t\left(\beta_{j}\right)=\beta_{1, j}\left[t\left(\beta_{1}\right)\left(\right.\right.$ Price $\left._{i j s}\right)+t\left(\beta_{2, j}\right)$ ASC $_{i j s}+t\left(\beta_{3, j}\right)$ Choice $_{i j s}+t\left(\beta_{4, j}\right)$ Premium $_{i j s}+$ $t\left(\beta_{5, j}\right)$ Organic $_{i j s}+t\left(\beta_{6, j}\right) U K_{i j s}+t\left(\beta_{7, j}\right) E U_{i j s}+t\left(\beta_{8, j}\right)$ OutsideE $U_{i j s}+$ $t\left(\beta_{9, j}\right)$ FreedomFood $_{i j s}+t\left(\beta_{10, j}\right)$ International $\left._{i j s}\right]$

where the $A S C_{i j s}$ captures the no choice option. Given that the no choice option takes no specific form it then follows that this parameter has no specific model interpretation (Balcombe and Fraser, 2011; Balcombe et al., 2016). Turning to the other model parameters, Choice and Premium capture product quality with the reference level assumed to be Basic; Organic is the type of farm production system with the reference level being Conventional; UK, EU and Outside EU are the CoO attribute with the reference level being a specific EU country; and Freedom Food and International describe farm assurance with the reference level being no indication of farm assurance. Finally, the transformation $t\left(\right.$.) can take one of two forms, $t\left(\beta_{k}\right)=\beta_{k}$ for $k>1$ or $t\left(\beta_{1}\right)=\exp \left(\beta_{1}\right)$. In the models presented, we only allow the Price attribute to be a log-normal random parameter whereas all other attributes are assumed to be normal. 


\subsection{Model Selection}

We begin by examining various model specifications for the different treatments considered. We estimate models for both $\mathrm{CoO}$ treatments as well as a model that pooled the data from both treatments. The model MargLL results are reported in Table 3.

Table 3: Values of Logged Marginal Likelihoods for Model Selection

\begin{tabular}{llllll}
\hline & \multicolumn{2}{l}{ Estimated Separately } & Unpooled & Pooled & Log BR In \\
\hline Products & No Flag (i) & Flag (ii) & (i + ii) & & $\begin{array}{l}\text { Favour of } \\
\text { Pooling }\end{array}$ \\
\hline Pork Sausage & -752.64 & -792.05 & -1544.70 & -1491.71 & 52.99 \\
Bacon & -743.82 & -773.13 & -1516.96 & -1468.57 & 48.38 \\
Lamb & -767.61 & -902.24 & -1669.86 & -1617.63 & 52.23 \\
Pork Leg & -748.55 & -677.75 & -1426.30 & -1380.88 & 45.42 \\
Beef Burger & -861.85 & -676.99 & -1538.85 & -1478.39 & 60.46 \\
Chicken Breast & -739.06 & -737.06 & -1476.13 & -1407.81 & 68.32 \\
Chicken Pie & -778.28 & -848.17 & -1626.46 & -1561.67 & 64.79 \\
Gammon & -758.12 & -754.99 & -1513.11 & -1457.49 & 55.62 \\
Turkey Mince & -794.34 & -650.08 & -1444.43 & -1386.12 & 58.31 \\
Lasagne & -742.02 & -734.21 & -1476.23 & -1413.53 & 62.70 \\
Chicken Madras & -657.19 & -859.02 & -1516.21 & -1465.10 & 51.12 \\
Pepperoni Pizza & -971.27 & -761.16 & -1732.43 & -1695.75 & 36.68 \\
\hline
\end{tabular}

As can be seen in Table 3 the joint MargLL for the data estimated by treatment (text and text and flag) compared to that for when the data is pooled is such that we prefer to report the pooled results. This finding holds for all 12 DCE. Therefore, it is the pooled model that we refer to in terms of WTP estimates reported. ${ }^{17}$

\subsection{WTP Estimates}

We report the WTP results in Tables 4.1 and 4.2. Our median and mean results are equivalent since we specified normal distributions for the WTPs. These WTP results need to be interpreted carefully and in the following way. In the case where there are two or more levels for an attribute, such as $\mathrm{CoO}$, then the results generated are relative to the selection of the base level (which is indicated in brackets). So in the case of Product Quality the estimates of WTP for Choice and Premium are relative to Basic Product Quality. With regard to $\mathrm{CoO}$ the estimates are measured relative to a specific EU country. So in the case of chicken breast the CoO WTP are relative to the Netherlands, the main source

\footnotetext{
${ }^{17}$ In order to reduce the number of tables included we focus specifically on WTP results. All pooled model results are available on request from the authors.
} 
of imports into the UK (BPEX, 2013a). Also, the WTP are for the given quantity of the product in question. So for example, for chicken breast the WTP estimates are for 500 grams of the product.

A summary of the mean (and median since they are equivalent to the mean given the normal distribution of the WTPs) WTP estimates along with lower (Lqrt) and upper (Uqrt) quartiles are reported in Tables 4.1 and 4.2. The standard deviations in parentheses are standard deviations for the mean (analogous to a standard error in classical terminology), whereas the lower and upper quartiles are estimates for the population distribution (thus including heterogeneity across the population)

Table 4.1: WTP Estimates (f) (Pooled Data)

\begin{tabular}{llllllllll}
\hline & \multicolumn{1}{l}{ Pork Sausages } & \multicolumn{3}{c}{ Pork Joint } & & \multicolumn{3}{l}{ Beef Lasagne } \\
\hline & Mean (Std) & Lqrt & Uqrt & Mean (Std) & Lqrt & Uqrt & Mean (Std) & Lqrt & Uqrt \\
\hline Choice & $0.17(.08)$ & -0.19 & 0.53 & $0.46(.33)$ & 0.009 & 0.92 & $0.87(.17)$ & 0.37 & 1.38 \\
Premium & $1.08(.15)$ & -0.1 & 2.26 & $2.40(.52)$ & 0.23 & 4.57 & $2.55(.25)$ & 0.25 & 4.83 \\
Organic & $0.91(.09)$ & 0.16 & 1.65 & $2.62(.30)$ & 0.69 & 4.54 & $1.92(.15)$ & 0.63 & 3.19 \\
UK & $0.84(.10)$ & 0.49 & 1.18 & $3.15(.50)$ & 2.25 & 4.06 & $1.68(.24)$ & 1.39 & 1.96 \\
EU & $-0.27(.10)$ & -0.74 & 0.2 & $-1.09(.34)$ & -2.05 & -0.12 & $-1.0(.18)$ & -2.1 & 0.11 \\
Outside EU & $-0.73(.14)$ & -1.14 & -0.31 & $-2.28(.65)$ & -3.06 & -1.50 & $-0.71(.29)$ & -1.15 & -0.26 \\
Freedom Food & $0.33(.10)$ & 0.05 & 0.61 & $1.68(.40)$ & 1.29 & 2.06 & $0.96(.18)$ & 0.67 & 1.25 \\
International & $0.87(.12)$ & 0.11 & 1.64 & $2.42(.41)$ & 0.37 & 4.48 & $1.68(.21)$ & -0.35 & 3.64 \\
\hline & Bacon & & & Beef Burger & & & Chicken Curry & \\
\hline & Mean (Std) & Lqrt & Uqrt & Mean(Std) & Lqrt & Uqrt & Mean (Std) & Lqrt & Uqrt \\
\hline Choice & $0.35(.09)$ & 0.06 & 0.64 & $0.49(.09)$ & 0.1 & 0.88 & $0.4(.11)$ & -0.02 & 0.81 \\
Premium & $0.88(.12)$ & 0.12 & 1.66 & $1.02(.15)$ & -0.32 & 2.35 & $1.45(.19)$ & -0.1 & 2.99 \\
Organic & $0.93(.08)$ & 0.24 & 1.61 & $0.67(.09)$ & -0.22 & 1.57 & $1.29(.13)$ & 0.03 & 2.55 \\
UK & $0.67(.13)$ & 0.44 & 0.9 & $0.65(.10)$ & 0.29 & 1.02 & $1.16(.14)$ & 0.67 & 1.66 \\
EU & $-0.62(.10)$ & -1.17 & -0.07 & $-0.77(.09)$ & -1.19 & -0.34 & $-0.41(.11)$ & -0.9 & 0.06 \\
Outside EU & $-1.04(.17)$ & -1.35 & -0.74 & $-0.86(.18)$ & -1.91 & 0.16 & $-0.87(.21)$ & -1.84 & 0.11 \\
Freedom Food & $0.6(.11)$ & 0.35 & 0.85 & $0.48(.10)$ & 0.17 & 0.8 & $0.52(.13)$ & 0.14 & 0.89 \\
International & $0.85(.11)$ & 0.12 & 1.58 & $0.85(.12)$ & -0.08 & 1.78 & $1.19(.16)$ & -0.08 & 2.46
\end{tabular}

Notes: Reference levels: for Choice and Premium it is Basic; for Organic it is conventional; for UK, EU and Outside EU it is a specific EU country; and for Freedom Food and Internal it is no label. Additionally note that the reported means are also the medians since the distributions are normal for these parameters. The standard deviations in parentheses (Std) are standard deviations for the mean, whereas the lower and upper quartiles are estimates for the population distribution. 
Table 4.2: WTP Estimates (f) (Pooled Data)

\begin{tabular}{|c|c|c|c|c|c|c|c|c|c|}
\hline & \multicolumn{3}{|l|}{ Leg Lamb } & \multicolumn{3}{|c|}{ Chicken Breasts } & \multicolumn{3}{|c|}{ Pepperoni Pizza } \\
\hline & Mean (Std) & Lqrt & Uqrt & Mean (Std) & Lqrt & Uqrt & Mean (Std) & Lqrt & Uqrt \\
\hline Choice & $0.5(.25)$ & 0.2 & 0.8 & $0.63(.18)$ & 0.38 & 0.89 & $0.51(.15)$ & 0.25 & 0.77 \\
\hline Premium & $1.69(.34)$ & 0.74 & 2.64 & $1.4(.27)$ & 0.34 & 2.47 & $1.59(.22)$ & 0.44 & 2.74 \\
\hline Organic & $2.03(.24)$ & 0.38 & 3.67 & $2.06(.31)$ & 0.42 & 3.69 & $1.48(.15)$ & 0.48 & 2.47 \\
\hline UK & $2.85(.35)$ & 2.04 & 3.65 & $2.23(.31)$ & 1.83 & 2.63 & $0.91(.21)$ & 0.65 & 1.17 \\
\hline EU & $-2.62(.34)$ & -3.66 & -1.57 & $-0.38(.26)$ & -0.98 & 0.23 & $-0.95(.21)$ & -1.85 & -0.06 \\
\hline Outside EU & $0.03(.45)$ & -0.77 & 0.82 & $-1.99(.36)$ & -2.42 & -1.57 & $-0.5(.27)$ & -0.85 & -0.15 \\
\hline Freedom Food & $1.68(.29)$ & 1.15 & 2.2 & $1.41(.20)$ & 1.0 & 1.83 & $1.35(.21)$ & 0.88 & 1.84 \\
\hline \multirow[t]{3}{*}{ International } & $1.43(.36)$ & 0.37 & 2.48 & $1.7(.40)$ & 0.2 & 3.2 & $1.31(.21)$ & 0.31 & 2.29 \\
\hline & \multicolumn{3}{|l|}{ Chicken Pie } & \multicolumn{3}{|c|}{ Gammon Steaks } & \multicolumn{3}{|c|}{ Turkey Mince } \\
\hline & Mean (Std) & Lqrt & Uqrt & Mean (Std) & Lqrt & Uqrt & Mean (Std) & Lqrt & Uqrt \\
\hline Choice & $0.43(.10)$ & 0.06 & 0.8 & $0.52(.14)$ & 0.21 & 0.82 & $0.32(.10)$ & 0.01 & 0.62 \\
\hline Premium & $1.37(.17)$ & 0.02 & 2.73 & $1.44(.20)$ & -0.06 & 2.93 & $1.05(.15)$ & 0.03 & 2.06 \\
\hline Organic & $1.02(.14)$ & 0.01 & 2.02 & $1.06(.13)$ & 0.09 & 2.02 & $1.21(.08)$ & 0.6 & 1.82 \\
\hline UK & $0.72(.12)$ & 0.46 & 0.98 & $1.59(.20)$ & 1.1 & 2.07 & $1.12(.13)$ & 0.81 & 1.43 \\
\hline EU & $-0.86(.14)$ & -1.48 & -0.23 & $-0.64(.14)$ & -1.13 & -0.15 & $-0.14(.10)$ & -0.48 & 0.2 \\
\hline Outside EU & $-0.76(.20)$ & -1.39 & -0.11 & $-1.31(.24)$ & -1.84 & -0.78 & $-1.01(.17)$ & -1.36 & -0.65 \\
\hline Freedom Food & $0.55(.14)$ & 0.21 & 0.9 & $0.8(.16)$ & 0.55 & 1.07 & $0.69(.11)$ & 0.34 & 1.03 \\
\hline International & $1.18(.15)$ & 0.02 & 2.34 & $0.75(.17)$ & -0.39 & 1.88 & $1.03(.11)$ & 0.18 & 1.89 \\
\hline
\end{tabular}

Notes: Reference levels: for Choice and Premium it is Basic; for Organic it is conventional; for UK, EU and Outside EU it is a specific EU country; and for Freedom Food and Internal it is no label. Additionally note that the reported means are also the medians since the distributions are normal for these parameters. The standard deviations in parentheses (Std) are standard deviations for the mean, whereas the lower and upper quartiles are estimates for the population distribution.

In general the results in Tables 4.1 and 4.2 confirm prior expectations. We observe for all products examined that respondents have relatively strong preferences for Premium Quality produce, produced within an organic production system and produced in the UK. There are also positive preferences displayed for the Farm Assurance attribute with stronger preferences for International Quality over Freedom Food. The finding regarding the Freedom Food attribute may in part be traced back to public recognition and understanding. As noted by McNair et al. (2013):

"106. The FF scheme will thrive in future only if it achieves a significant level of recognition among consumers. It is demand for FF products that ultimately ensures the scheme's survival. At the moment, the degree of recognition of the FF label among consumers is low."

Turning to $\mathrm{CoO}$, we observe a consistent set of results. The UK CoO attribute is always the most preferred, followed by a specific EU country (that differed between products). So for example, when it comes to chicken pie (bottom set of products) the median WTP for UK CoO is 72 pence for a two person portion pie. The next preferred option (albeit negatively valued relative to the named EU 
country which in this case is Ireland) is the non-EU product, with the generic EU product the least preferred. Thus, for the outside EU country, which in the case of chicken pie was Brazil, respondents require a 76 price reduction compared to the named EU country, Ireland.

In general, these results confirm findings reported in the literature that show a strong home country bias against identical products from other countries. For example, Pouta et al. (2010) report that Swedish consumers' value home country broiler meat over that from Denmark, and this is preferred to meat from Brazil and Thailand. Similarly, for beef steaks Lim et al. $(2013,2014)$ find that US consumers prefer domestic meat over that from Canada which is preferred, albeit it only marginally, to meat from Australia. Kallis et al. (2011) and Kallis and Gil (2012) reported the same pattern of preferences for Spanish consumers and rabbit. Thus, the preferences exhibited by our respondents for other identified EU countries over non-identified EU and non-EU countries is generally in accordance with previously reported research in the literature that has shown that distance, geographically and potentially culturally, has an impact on CoO WTP. ${ }^{18}$

When we consider size of the WTP estimates relative to those already reported in the literature we can see that the magnitude of our estimates is not that large. For example, although within the DCE reported here the magnitude of the results for Beef Lasagne, are relatively high, this is for a $600 \mathrm{~g}$ product that serves at least two people. However, when we compare our estimates with Boeri et al. (2014) who examined consumers' preferences for lasagne in six EU countries the size of our WTP for $\mathrm{CoO}$ are somewhat smaller.

Of course another way in which to gauge the magnitude of our WTP estimates is to consider relative values in terms of percentage changes. Looking at our median WTP estimates for UK CoO, we can see that nearly all are less than $50 \%$ of the mid-point of the domestic price range for all 12 products examined in the study (the exception being Beef Lasagne) with an average of 39\% (See Appendix Table A2 for details). This implies that at average market prices for the specific set of goods consumed, UK consumers appear to be willing to pay no more than $50 \%$ for a product that is from the UK compared to an alternative from outside the EU. Clearly, this implies that our respondents appear willing to pay a premium for UK products, or require price discounts if they are to consider buying non-UK products.

Although 39\% might appear to be somewhat high, our estimates are certainly in keeping with many of those already reported in the literature and, if anything, are at the lower end of the estimates reported to date. For example, if we compare our estimates to those reported in Lim et al. (2013,

\footnotetext{
${ }^{18} \mathrm{An}$ exception to this result is provided by Maes et al. (2014) who reported their highest WTP for non-UK beef to be for France and this is greater than the estimates for Argentina, Brazil and the USA.
} 
2014) and Meas et al. (2014), which are all for beef, our estimates are most certainly not overly large. Indeed, if we consider the lower quartile estimates for all products reported in Table 4, then our WTP estimates are often less than $25 \%$ of the mid-point of the domestic price for all products and this is a relatively small value for $\mathrm{CoO}$ compared to those reported in many of the hypothetical DCE literature cited in Table 1.

As an example of the percentage changes involved, consider chicken breast which yields relatively high percentage estimates. The median WTP for UK over a named EU country reported in Table 4.2 is $£ 2.23$. The average market price for this product is $£ 4.50$ which means that the WTP estimate is approximately $50 \%$ of this price. When we consider the lower quartile value, which $f 1.83$ this then equates to $40 \%$ of the price. In contrast, when we consider beef burgers, we see that the median WTP is $22 \%$ of the average market price and only $10 \%$ when we consider the lower quartile estimate.

Potentially, our most important result emerges when we consider the differences between the fresh, chilled and frozen products and the processed products. First, we see that UK CoO is not the most highly valued (i.e., ranked) attribute for eight products. This is important as it indicates that although UK CoO does attract a reasonably high premium, it is not the largest. Thus, there would appear to be reason to assume that the relative values attached to $\mathrm{CoO}$ do vary by product. We would also contend that given the relative rank of the estimates, that for many of the products considered $\mathrm{CoO}$ is likely to be valued somewhat less than our point estimates indicate.

Second, the times when UK CoO is most important it is for the fresh/chilled/frozen group of products (excluding chicken) and for gammon steak, which many consumers may consider fresh. The fact that there is this pattern of results for UK CoO would indicate that for processed products the quality signal provided by the quality attribute or the organic production system are of greater importance. This relative effect is potentially important as it suggests that $\mathrm{CoO}$ is most likely to be meaningfully employed only in purchase decisions for fresh/chilled/frozen meat.

Third, for some of the products we have examined there is an asymmetric response to the CoO that indicates that although UK $\mathrm{CoO}$ is valued, it is not necessarily the most important piece of information. What appears to be relatively more important is knowing that a product is not from the UK, especially if it is from a distant country to the UK. In these cases the introduction of $\mathrm{CoO}$ may well lead to a change in purchase choices that could have potential impacts on the level of imports accompanied by 
an increasing demand for domestic production that might be met by increased supply or increases in price. ${ }^{19}$

\subsection{Choice Consistency: Attribute Attendance and Attribute Ranking}

After completing all the choice cards, respondents were asked two sets of questions about how they ranked the importance of attributes and whether they ignored attributes when making their choices. Answers to these questions can be used to cross check how people interacted with the survey instrument, and are an additional source of information about how people respond to attributes. If people indicate that they did not ignore an attribute they are said to have "attended" that attribute. Ideally, all respondents would attend all attributes. However, studies that have asked attendance questions, have generally found that some people do not attend all attributes, with non-attendance increasing with the complexity of tasks (commonly $50 \%$ to $100 \%$ of people not attending at least one attribute). While this may appear to be a source of concern, the literature has fortunately established that people who state that they have not attended an attribute have probably paid attention to it when making their choices, though they generally give it less importance. The ranking of attributes provides a complementary source of information which can be used to check the non-attendance data. There is evidence that this is more reliable than non-attendance data (Balcombe et al., 2015). Here, on average about $85 \%$ of people did not attend at least one attribute.

Within this study, across all 12 products, non-attendance was fairly consistent for all attributes (range $15 \%$ to $35 \%$ for different attributes). This is consistent with previous studies we have conducted (Balcombe et al., 2015). In both the ranking and attendance questions, Product Quality was clearly the most important attribute. CoO was consistently of mid-range importance according to both the ranking and attendance measures. The ranking and attendance measures assigned different levels of importance (on average) to Price, being the least attended attribute. However, the ranking of Price generally indicated that it was the second most important attribute across most products, giving us some confidence that people did pay attention to the price.

\subsection{Format of $\mathrm{CoO}$}

Once all the DCE data had been collected we asked all respondents their preferred format for CoO. We found that a text and flag format was preferred by $41.7 \%$ of respondents which was slightly more than flag only (40.8\%) with text only preferred by just $17.5 \%$ of respondents. Thus, respondents do

\footnotetext{
${ }^{19}$ There is limited research examining trade effects that result from the introduction of $\mathrm{CoO}$. See Baltussen et al. (2013) and Carlsson et al. (2014) for examples currently reported in the literature.
} 
appear to have a strong preference for a format that employs a flag. However, what is interesting is that the actual difference in WTP with and without a flag is minimal and as such the preferred format does not appear to necessarily influence choice.

\section{Discussion and Conclusions}

In this paper, we reported the results for 12 DCE that have considered the issue of $\mathrm{CoO}$ for meat and meat products in the UK. The results presented are for many products the first available in the literature. In addition, the results have considered how to present $\mathrm{CoO}$ information with specific reference to current legislation, also an important feature of the study. In addition, the analysis considered the format of the $\mathrm{CoO}$ attribute in examining product choice with the use of text only or with a flag. Although we assumed a priori that the $\mathrm{CoO}$ attribute format might be important, we only observed marginal changes in WTP and as such we conclude that specific format design does not appear to be very important with regard to $\mathrm{CoO}$ in this study.

Based on our findings we are now in a position to address the research questions we identified in the Introduction. Our first question asked if we could simply transfer point value estimates from existing studies on $\mathrm{CoO}$ to the products covered by the extension of mandatory $\mathrm{CoO}$ in the EU. The answer to this question is no. There is a significant degree of variation in the point estimates for $\mathrm{CoO}$ for the set of products we have considered. There is also significant variation in our $\mathrm{CoO}$ estimates when we examine these as a percentage of the mid-price level employed within the DCE. Overall, our point estimates and percentage values for $\mathrm{CoO}$ do differ somewhat between the set of products we have examined, and these estimates are typically lower than many previously reported in the literature. Also, these results are for UK consumers and it does not follow that they will be replicated if similar studies are conducted in other countries and as such caution needs to be exercised if researchers use these estimates in benefit transfer.

In addition, we have found that for four products UK $\mathrm{CoO}$ is the most highly valued attribute; these tend to be fresh/chilled/frozen products. Importantly, these products are now subject to mandatory $\mathrm{CoO}$ (since the $1^{\text {st }}$ April 2015). Furthermore, these results confirm that we cannot infer that consumers will place a high/low value on $\mathrm{CoO}$ simply because such a result has previously been reported in literature for seemingly similar products. Our results also reveal that consumers do appear to value CoO not only in terms of a UK (i.e., home country) label, but also labels that indicate the source of meat from elsewhere. 
Turning to our second question about further extending mandatory $\mathrm{CoO}$ there appears to be limited positive evidence to support this policy change. Although we find positive estimates for $\mathrm{CoO}$ for all 12 products examined, for eight of the products the $\mathrm{CoO}$ attribute is far from being the most highly valued product attribute. For example, when we consider the percentage increase in UK CoO for beef burgers this is only $20 \%$ of the average market price, which is significantly lower than for chicken breast, a product for which $\mathrm{CoO}$ was highly valued. As a result $\mathrm{CoO}$ for this set of products is valued significantly less than the other attributes. Thus, we contend that our estimates provide at best only weak support for extending mandatory $\mathrm{CoO}$ to other meat products, certainly as far as consumers are concerned.

Furthermore, the reasons often advanced in the literature to justify the extension of mandatory CoO are potentially misplaced. Consumers may well seek and expect more information about a product's $\mathrm{CoO}$, but there is no reason to mandate the provision of this information if consumers do not value this sufficiently. There would appear to be, certainly for many of the products we have considered, stronger consumer preferences (i.e., place a higher value on) for other food attributes. Therefore, this suggests that there may be economic reasons to support the development of appropriate rules governing the provision of $\mathrm{CoO}$ on a voluntary basis that will meet the needs of consumers. EU policy makers might therefore focus on facilitating a voluntary approach which is consistent with the operation of the single market.

Of course to suggest a voluntary approach over a mandatory approach to $\mathrm{CoO}$ information provision for many of the meat products considered based on estimates of benefits alone is potentially misleading. We can, however speculate, that although we have not considered the industry costs of implementing $\mathrm{CoO}$ for meat, the limited research currently available suggests that costs need not be insignificant, although the limited research available is far from definitive. For example, the USDA (2015) report reductions in producer surplus as a result of implementing mandatory CoO for beef to be in excess of $\$ 1$ billion (US) over the course of 10 years. In contrast, research on EU mandatory CoO implementation for pork and poultry by Baltussen et al. (2013) indicates industry costs per kilogram for pork and poultry of between 2 and 5 eurocents per kilogram. Estimates of this magnitude indicate that mandatory $\mathrm{CoO}$ will not necessarily impose a large cost burden. In contrast, a qualitative benefit cost analysis reported by Carlsson et al. (2014) for Sweden finds in favour of voluntary CoO because of the potential costs to be borne by industry. In summary, the existing costs estimates of CoO implementation are far from definitive and making any formal quantitative benefit cost analysis very difficult. Furthermore, the scope of meat products considered is very limited with the studies to date focusing on non-processed products that are likely to be the least complicated and costly when it comes to $\mathrm{CoO}$ implementation. Therefore, before a definitive conclusion can be offered on mandatory versus voluntary, far more work on the costs of $\mathrm{CoO}$ implementation is required. 
Finally, in addition to the empirical results we have produced, our study has also revealed as part of the DCE design that the type of data required to enable identification of the origin of meat in many food products is not always readily available in the public domain. In this study, we have found that the link between primary production, the movement of meat through the supply chain and the resulting use of meat in processed food products is hard to establish. This is not surprising as food manufacturing and processing has become ever more important in terms of supplying the food products demanded by consumers (Popkin, 2014; Gollin and Probst, 2015). Furthermore, it is the complexity of the supply chain that is in large part responsible for the horsemeat incident in the EU in 2013 whereby there was undeclared intentional substitution of beef with horsemeat in various processed products. This incident has raised awareness of the country of origin of food but it is far from clear if mandatory $\mathrm{CoO}$ is the correct policy response. Indeed, the implications of this complexity raises questions about how consumers will value and use $\mathrm{CoO}$ when the information required becomes difficult to convey in a simple and meaningful manner. 


\section{References}

Awada, L. and Yiannaka, A. (2012). Consumer Perceptions and the Effects of Country of Origin Labeling on Purchasing Decisions and Welfare. Food Policy, 37: 21-30.

Balcombe, K.G., Chalak, A. and Fraser, I.M. (2009). Model Selection in the Bayesian Mixed Logit. Journal of Environmental Economics and Management, 57(2): 226-237.

Balcombe, K.G., Fraser, I.M. and Di Falco, S. (2010). Traffic Lights and Food Choice: A Choice Experiment Examining the Relationship Between Food Labels and Price. Food Policy, 35(3): 211-220.

Balcombe, K.G. and Fraser, I.M. (2011). A General Treatment of Non-Response Data from Choice Experiments using Logit Models. European Review of Agricultural Economics, 38(2): 171-191.

Balcombe, K.G., Fraser, I.M. and McSorley, E. (2015). Attribute Non-Attendance and Choice Experiments: Using Eye-Tracking to Understand Respondent Behaviour. Journal of Applied Econometrics, 30(3): 447-467.

Balcombe, K.G., Fraser, I.M., Lowe, B. and Souza-Monteiro, D. (2016). Attribute Non-Attendance and Attribute Importance Ranking Responses within Discrete Choice Experiments. American Journal of Agricultural Economics, 98(1): 54-73.

Baltussen, W., Jongeneel, R., Helming, J., Dewar, D., Van Horne, P. (2013). Study on mandatory origin labelling for pig, poultry and sheep \& goat meat AGRI-2012-EVAL-01. Brussels, European Commission, http://ec.europa.eu/agriculture/external-studies/2013/origin-labelling/fulltext en.pdf

Bienenfeld, J.M., Botkins, E.R., Roe, B.E. and Batte, M.T. (2016). Country of Origin Labeling for Complex Supply Chains: Th Case for Labeling the Location of Different Supply Chain Links. Agricultural Economics, 47: 205-213.

Boeri, M., Brown, H. and Longo, A. (2014). The Implications Across Europe of the "Horse Meat Scandal" on the Monetary Value of Meat Authenticity and Food Safety in Ready to Heat Lasagne: Evidence from Six Countries, Paper presented at EAAE 2014 Congress, Ljubljana, Slovenia. 
Bonroy, O. and Constantatos, C. (2015). On the Economics of Labels: How Their Introduction Affects the Functioning of Markets and the Welfare of All Participants. American Journal of Agricultural Economics, 97(1): 239-259.

BPEX (2013a). Poultry Pocketbook 2013, Agriculture and Horticulture Development Board, Stoneleigh Park, Kenilworth, Warwickshire.

BPEX (2013b). Pig Pocketbook 2013, Agriculture and Horticulture Development Board, Stoneleigh Park, Kenilworth, Warwickshire.

Carlsson, C., Johansson, H., Lagerkvist, C.J., Sundstrom, K. and Wilhelmsson, F. (2014). Origin Labelling of Food - Costs and Benefits of New EU Legislation for Sweden, Report 2014:1, AgriFood Economics Centre, Lund, Sweden (www.agrifood.se).

ChoiceMetrics. (2012). Ngene 1.1.1 User Manual \& Reference Guide, Australia. Available online at www.choice-metrics.com.

Colson, G., Corrigan, J.R., Grebitus, C., Loureiro, M.L. and Rousu, M.C. (2015). Which Deceptive Practices, If Any, Should Be Allowed in Experimental Economics Research? Results from Surveys of Applied Experimental Economists and Students. American Journal of Agricultural Economics, 98 (2): 610-621.

Costanigro, M. and McCluskey, J. (2011). Hedonic Price Analysis in Food Markets. Chapter 6, p. 152180, The Oxford Handbook of the Economics of Food Consumption and Policy, edited by Jayson L. Kusk, Jutta Roosen and Jason F. Shogren. Oxford University Press.

Defra (2012). Green Food Project Curry Sub Group Report, July, www.defra.gov.au.

Deselnicu, O.C., Costanigro, M., Souza-Monteiro, D.M. and Thilmany McFadden, D. (2013). A metaAnalysis of Geographical Indication Food Valuation Studies: What Drives the Premium for Origin-Based labels. Journal of Agricultural and Resource Economics, 38(2): 204-219.

EBLEX (2014a). UK Yearbook 2014 Sheep, Agriculture and Horticulture Development Board, Stoneleigh Park, Kenilworth, Warwickshire. 
EBLEX (2014b). UK Yearbook 2014 Cattle, Agriculture and Horticulture Development Board, Stoneleigh Park, Kenilworth, Warwickshire.

FCEC: Agra CEAS Consulting (2013). Study on the mandatory indication of origin or place of provenance of meat used as an ingredient. Final Report for the European Commission. July 2013.

FCEC: Agra CEAS Consulting (2014). Study on the mandatory indication of origin or place of provenance of unprocessed foods, single ingredient products and ingredients that represent more than $50 \%$ of a food. Final Report for the European Commission. September 2014.

Font I Furnols, M., Realini, C., Montossi, F., Sanudo, C., Campo, M.M., Oliver, M.A., Nute, G.R. and Guerrero, L. (2011). Consumer's Purchasing Intention for Lamb Meat Affected by Country of Origin, Feeding System and meat price: A Conjoint Study in Spain, France and United Kingdom. Food Quality and Preference, 22: 443-451.

Gao, Z. and Schroeder, T.C. (2009). Effects of Label Information on Consumer Willingness-to-Pay for Food Attributes. American Journal of Agricultural Economics, 91(3): 795-809.

Gollin, D. and Probst, L.T. (2015). Food and Agriculture: Shifting Landscapes for Policy. Oxford Review of Economic Policy, 31(1): 8-25.

Grebitus, C., Colson, G. and Menapace, L. (2012). A Comparison of Hypothetical Survey Rankings with Consumer Shopping Behavior. Journal of Agricultural and Applied Economics, 44(1): 35-47.

Greene W.H. and D.A. Hensher. 2010. Does Scale Heterogeneity Across Individuals Matter? An Empirical Assessment of Alternative Logit Models. Transportation, 37(3): 413-428.

Hussein, M., Fraser, I. and Costanigro, M. (2016). Hedonic Analysis of Origin of Meat in the United Kingdom. Contributed paper presented at $90^{\text {th }}$ Annual Conference of the Agricultural Economics Society, University of Warwick, April 2016.

Jongeneel, R. and Baltussen, W. (2014). Analyzing the Impacts of Mandatory Country of Origin Labeling in EU Pork and Poultry Sectors on Markets, Cost of Production and Trade, Paper presented at $14^{\text {th }}$ EAAE Congress, Lubljana, Slovenia. 
Joseph, S., Lavoie, N. and Caswell, J.A. (2014). Implementing COOL: Comparative Welfare Effects of Different Labeling Schemes. Food Policy, 44: 14-25.

Kallas, Z. and Gil, J.M. (2012). A Dual Response Choice Experiment (DRCE) Design to Assess Rabbit Meat Preference in Catalonia. A Heteroscedastic Extreme-Value Model. British Food Journal, 114(10): 1394-1413.

Kallas, Z., Lambarraa, F. and Gil, J.M. (2011). A Stated Preference Analysis Comparing the Analytical Hierarchy Process Versus Choice Experiments. Food Quality and Preference, 22: 181-192.

Klain, T.J., Lusk, J.L., Tonsor, G.T. and Schroeder, T.C. (2014). An Experimental Approach to Valuing Information. Agricultural Economics, 45: 635-648.

Lagerkvist, C.J., Berthelsen, T., Sundstrom, K. and Johansson, H. (2014). Country of Origin or EU/nonEU Labelling of Beef? Comparing Structural Reliability and Validity of Discrete Choice Experiments for Measurement of Consumer Preferences for Origin and Extrinsic Quality Cues. Food Quality and Preference, 34: 50-61.

Lee, S.H., Han, D.B., Caputo, V. and Nayga Jr., R.M. (2015). Consumers' Valuation for a Reduced Salt Product: A Nonhypothetical Choice Experiment. Canadian Journal of Agricultural Economics, 63: 563582.

Lim, K.H., Hu, W., Maynard, L.J., and Goddard, E. (2013). U.S. consumers' preference and willingness to pay for country-of-origin-labeled beef steak and food safety enhancements. Canadian Journal of Agricultural Economics. 61(1), 93-118.

Lim, K.H., Hu, W., Maynard, L.J., and Goddard, E. (2014). A Taste for Safer Beef? How Much Does Consumers' Perceived Risk Influence Willingness to pay for Country-of-Origin Labeled Beef. Agribusiness, 30(1): 17-30.

List, J.A. and Gallet, C.A. (2001). What Experimental Protocol Influence Disparities Between Actual and Hypothetical Stated Values? Environmental and Resource Economics, 20:241-254.

Loureiro, M.L., and Umberger, W. J (2003). Estimating Consumer Willingness to Pay for Country-ofOrigin Labeling. Journal of Agricultural and Resource Economics, 28(2):287-301. 
Loureiro, M.L., and Umberger, W. J (2007). A choice experiment model for beef: What US consumer responses tell us about relative preferences for food safety, country-of-origin labeling and traceability. Food Policy, 32: 496-514

Louviere, J.J., D.A. Hensher, and J.D. Swait (2000). Stated Choice Methods Analysis and Application. Cambridge University Press, UK.

Lusk, J.L. and Briggeman, B.C. (2009). Food Values. American Journal of Agricultural Economics, 91(1): 184-196.

Lusk, J.L. and Schroeder, T.C. (2004). Are Choice Experiments Incentive Compatible? A Test with Quality Diiferentiated Beef Steaks. American Journal of Agricultural Economics, 86: 467-482.

Lusk, J.L., Schroeder, T.C. and Tonsor, G.T. (2014). Distinguishing Beliefs from Preferences in Food Choice. European Review of Agricultural Economics, 41(4): 627-655.

Meas, T., Hu, W., Grebitus, C. and Colson, G. (2014). The Effects of Country of Origin Image and Patriotism on British Consumers' Preference for Domestic and Imported Beef, Selected Paper prepared for presentation at the Agricultural and Applied Economics Association's 2014 AAEA Annual Meeting, Minneapolis, MN, July 27-29, 2014.

Morkbak, M.R., Christensen, T. and Gyrd-Hansen, D. (2010). Choke Price Bias in Choice Experiments. Environmental and Resource Economics, 45: 537-551.

Moser, R., Raffaelli, R. and Notaro, S. (2014). Testing Hypothetical Bias with a Real Choice Experiment Using Respondents' Own Money. European Review of Agricultural Economics, 41(1): 25-46.

Popkin, B.M. (2014). Nutrition, Agriculture and the Global Food System in Low and Middle Income Countries. Food Policy, 47: 91-96.

Pouliot, S. and Sumner, D.A. (2014). Differential Impacts of Country of Origin Labeling: COOL Econometric Evidence from Cattle Markets. Food Policy, 49: 107-116. 
Pouta, E., Heikkila, J., Forman-Hugg, S., Isoniemi, M. and Makela, J. (2010). Consumer Choice of Broiler Meat: The Effects of Country of Origin and Production Methods. Food Quality and Preference, 21: 539-546.

Roe, B.E., M.F. Teisl and C.R. Deans. (2014). The Economics of Voluntary Versus Mandatory Labels. Annual Review of Resource Economics, 6: 407-427.

Tonsor, G.T., Schroder, T.C. and Lusk, J.L. (2013). Consumer Valuation of Alternative Meat Origin Labels. Journal of Agricultural Economics, 64(3): 676-692.

Umberger,W.J., (2010), Country of Origin Labelling: A Review of the Relevant Literature on Consumer Preferences, Understanding, Use and Willingness-to-Pay for CoOL of Food and Meat, Food Standards Agency Australia New Zealand. Accessible from: http://www.foodstandards.gov.au/code/proposals/documents/P1011\%20CoOL\%20AR\%20SD2\%20Li t\%20Review.pdf

USDA (2015). Economic Analysis of Country of Origin Labeling (COOL). Report to Congress, US Department of Agriculture, Office of the Chief Economist, Washington, D.C. http://www.agripulse.com/Uploaded/USDACOOLEconomicReport.pdf

Verbeke, W. and Roosen, J. (2009). Market Differentiation Potential of Country-of-Origin, Quality and Traceability Labeling. The Estey Centre Journal of International Law and Trade Policy, 10(1): 20-35. 
Appendix: Table A1: Sample Descriptive Statistics

\begin{tabular}{|c|c|c|c|c|c|c|c|}
\hline & Sample & 1 & 2 & 3 & 4 & 5 & 6 \\
\hline & Size & 490 & 495 & 492 & 492 & 492 & 490 \\
\hline \multirow[t]{2}{*}{ Gender } & Female & 64 & 62 & 65 & 59 & 64 & 52 \\
\hline & Male & 36 & 39 & 35 & 41 & 36 & 48 \\
\hline \multirow[t]{6}{*}{ Age } & $18-25$ & 15 & 16 & 16 & 14 & 14 & 9 \\
\hline & $26-35$ & 16 & 14 & 17 & 14 & 16 & 16 \\
\hline & $36-45$ & 18 & 18 & 14 & 18 & 17 & 17 \\
\hline & $46-55$ & 21 & 21 & 18 & 20 & 18 & 20 \\
\hline & $56-65$ & 19 & 21 & 24 & 21 & 22 & 20 \\
\hline & Over 66 & 11 & 11 & 10 & 13 & 13 & 18 \\
\hline \multirow[t]{11}{*}{ Region } & North East & 6 & 6 & 5 & 6 & 5 & 5 \\
\hline & North West & 15 & 14 & 13 & 13 & 14 & 13 \\
\hline & Scotland & 6 & 8 & 8 & 8 & 11 & 7 \\
\hline & Yorkshire & 8 & 12 & 11 & 9 & 8 & 11 \\
\hline & East Midlands & 8 & 9 & 7 & 8 & 7 & 7 \\
\hline & West Midlands & 8 & 8 & 9 & 8 & 8 & 11 \\
\hline & East of England & 8 & 9 & 6 & 5 & 7 & 7 \\
\hline & London & 11 & 11 & 11 & 10 & 16 & 11 \\
\hline & South East & 16 & 14 & 15 & 18 & 14 & 16 \\
\hline & South West & 8 & 7 & 10 & 8 & 7 & 8 \\
\hline & Wales & 5 & 4 & 4 & 7 & 4 & 4 \\
\hline \multirow[t]{3}{*}{ Marital Status } & Married / Partner & 56 & 59 & 57 & 61 & 60 & 66 \\
\hline & Single & 30 & 30 & 30 & 25 & 27 & 21 \\
\hline & Other & 14 & 12 & 13 & 14 & 13 & 13 \\
\hline \multirow[t]{5}{*}{ Children } & 0 & 68 & 74 & 70 & 68 & 66 & 65 \\
\hline & 1 & 15 & 14 & 14 & 15 & 14 & 15 \\
\hline & 2 & 13 & 10 & 12 & 13 & 15 & 13 \\
\hline & 3 & 3 & 2 & 4 & 3 & 3 & 5 \\
\hline & 4 or more & 1 & 1 & 0 & 2 & 2 & 2 \\
\hline \multirow[t]{6}{*}{ Education } & School to 16 & 27 & 20 & 22 & 24 & 22 & 24 \\
\hline & A-level or equivalent & 19 & 20 & 22 & 21 & 18 & 17 \\
\hline & Further education & 19 & 21 & 22 & 22 & 21 & 19 \\
\hline & Undergraduate & 25 & 28 & 23 & 21 & 26 & 27 \\
\hline & Post-graduate & 9 & 11 & 11 & 11 & 12 & 12 \\
\hline & Higher & 2 & 1 & 1 & 1 & 2 & 1 \\
\hline \multirow[t]{4}{*}{ Income (f/pa) } & $>5000$ & 7 & 5 & 6 & 5 & 4 & 2 \\
\hline & $5001-10,000$ & 8 & 6 & 8 & 9 & 8 & 7 \\
\hline & $10,001-20,000$ & 21 & 24 & 23 & 22 & 20 & 21 \\
\hline & \multicolumn{7}{|c|}{36} \\
\hline
\end{tabular}




\begin{tabular}{llllllll} 
& $\mathbf{2 1 , 0 0 1 - 3 0 , 0 0 0}$ & 16 & 19 & 18 & 14 & 16 & 21 \\
& $\mathbf{3 0 , 0 0 1 - 4 0 , 0 0 0}$ & 13 & 13 & 14 & 17 & 16 & 18 \\
& $\mathbf{4 0 , 0 0 1 - 5 0 , 0 0 0}$ & 11 & 10 & 9 & 9 & 9 & 8 \\
& $\mathbf{5 0 , 0 0 1 - 6 5 , 0 0 0}$ & 6 & 6 & 6 & 8 & 7 & 8 \\
& $\mathbf{6 5 , 0 0 1 - 8 0 , 0 0 0}$ & 4 & 3 & 4 & 3 & 4 & 5 \\
& $<80,001$ & 1 & 2 & 3 & 2 & 3 & 4 \\
\hline Shopping & Undeclared & 13 & 13 & 10 & 11 & 14 & 6 \\
\hline Eat meat & I share & 71 & 72 & 72 & 72 & 71 & 75 \\
& Yes & 29 & 29 & 28 & 29 & 29 & 25 \\
\hline
\end{tabular}


Appendix: Table A2: WTP for UK CoO as a Percentage of Product Market Price

\begin{tabular}{llll}
\hline & Median & Lqrt & Uqrt \\
\hline Pork & 46.7 & 27.2 & 65.6 \\
Bacon & 26.8 & 17.6 & 36.0 \\
Leg Lamb & 21.9 & 15.7 & 28.1 \\
Chicken Pie & 24.1 & 15.4 & 32.8 \\
Pork Joint & 45.4 & 33.7 & 56.8 \\
Beef Burger & 21.7 & 9.7 & 34.0 \\
Chicken Breasts & 49.6 & 40.7 & 58.4 \\
Gammon Steaks & 45.4 & 31.4 & 59.1 \\
Beef Lasagne & 67.2 & 55.6 & 78.4 \\
Chicken Curry & 43.8 & 25.3 & 62.6 \\
Pepperoni Pizza & 30.8 & 22.0 & 39.7 \\
Turkey Mince & 44.8 & 32.4 & 57.2 \\
\hline Average & 39.0 & 27.2 & 50.7 \\
\hline
\end{tabular}

